\title{
ПЕДАГОГИЧЕСКИЕ ОСНОВЫ ФОРМИРОВАНИЯ ДИДАКТИКО-МЕТОДИЧЕСКОЙ КОМПЕТЕНТНОСТИ БУДУЩИХ УЧИТЕЛЕЙ ИНФОРМАТИКИ
}

\section{PEDAGOGICAL FOUNDATIONS FOR THE FORMATION OF DIDACTIC-METHODICAL COMPETENCE OF FUTURE TEACHERS OF INFORMATICS}

\section{E. Favorskaia}

Summary: The article proposes a model for the formation of didacticmethodical competence, represented by components, with a description of their functional purpose; levels of formation; stages, as well as criteria for the formation of each component of the didactic-methodical competence of the future teacher of informatics. The model allows to consider the process of the formation of the didactic-methodical competence of the future teacher while studying at the university continuously and systematically, as well as to develop methods for the formation of didactic-methodical competence.

Keywords: didactic-methodical competence; future teacher of informatics; structural-functional model; methodology.

\author{
Фаворская Екатерина Александровна \\ старший преподаватель, Астраханский \\ государственный университет, г. Астрахань, \\ favorskayaea@mail.ru
}

Аннотация: В статье предложена модель формирования дидактико-методической компетентности, представленная компонентами, с описанием их функционального назначения; уровнями сформированности; этапами, а также критериями сформированности каждого компонента дидактико-методической компетентности будущего учителя информатики. Модель позволяет рассматривать процесс формирования дидактико-методической компетентности будущего учителя при обучении в ВУЗе непрерывно и системно, а также разрабатывать методики формирования дидактико-методической компетентности.

Ключевые слова: дидактико-методическая компетентность, будущий учитель информатики, структурно-функциональная модель, методика.
$\mathrm{O}$ дной из важнейших профессиональных компетентностей учителя является дидактико-методическая (ДМК). Согласно Н.В. Грызловой, «дидактико-методическая компетентность - системное образование, являющееся отдельно взятым видом профессионально-педагогической компетентности, ориентированной на знания, умения, навыки творческой педагогической деятельности будущего учителя, на формирование специальных умений профессиональной деятельности» $[2$, с. 14-35].

Актуальность темы исследования обусловлена необходимостью в определении методологических подходов к формированию ДМК, в разработке моделей ее формирования, выделении критериев сформированности ДМК учителя в конкретной предметной области для разработки методик формирования ДМК в процессе подготовки будущих учителей в ВУЗе.

Теоретической базой исследования послужили труды ученых по общей теории педагогики (В.А. Сластенина, А.А. Веневцевой, О.Б. Даутовой) и методики преподавания (Н.В. Грызловой, Ж.А. Мовсесян).

Практическая значимость исследования заключается
В том, что на основе предложенной модели формирования ДМК могут быть реализованы методики подготовки будущих учителей информатики при обучении в ВУЗе с использованием разнообразных средств, форм и методов обучения при формировании компонентов ДМК с учетом разработанных критериев.

Представим процесс формирования дидактико-методической компетентности будущих учителей информатики через систему взаимосвязанных между собой этапов.

\section{1 этап. Информашионно-мотивируюший}

Целями этапа являются создание условий для возникновения мотивации к профессионально-педагогической деятельности, формирование потребности и интереса к овладению необходимыми теоретическими и практическими знаниями и умениями. На данном этапе происходит формирование мотивационного и операционного компонентов (теория и практика по дисциплинам специальной и методической подготовки в конкретной предметной области, использование полученных знаний на учебной, технологической и педагогической практиках). 


\section{2 этап. Прик^адной}

Цели данного этапа заключаются в обеспечении условий для интеграции психолого-педагогической, специальной и методической подготовок, систематизации и актуализации знаний и умений, необходимых для решения как типовых, так и творческих профессиональных задач. На данном этапе осуществляется формирование мотивационного и операционного компонентов (осознание своего профессионального выбора, реализация технологии обучения, стратегия подготовки, определяются цели, формы работы, методы обучения) дидактикометодической компетентности.

\section{З этап. Рефлексивно-проектировочный}

Цели этапа: обеспечение условий для формирова- ния общепедагогических и методических (по конкретной предметной области) знаний и умений для формирования ДМК на основе рефлексии при анализе своей педагогической деятельности, результатов процесса обучения, прогнозирования затруднений обучающихся, проектирования образовательных траекторий обучающихся, проектирования деятельности по развитию личных общепедагогических и методических знаний, умений и всего процесса обучения в целом для повышения его эффективности. На данном этапе формируются все три компонента дидактико-методической компетентности: мотивационный, операционный и оценочный компоненты.

Отметим, что формирование каждого из компонентов дидактико-методической компетентности будущих учителей информатики происходит на протяжении не-

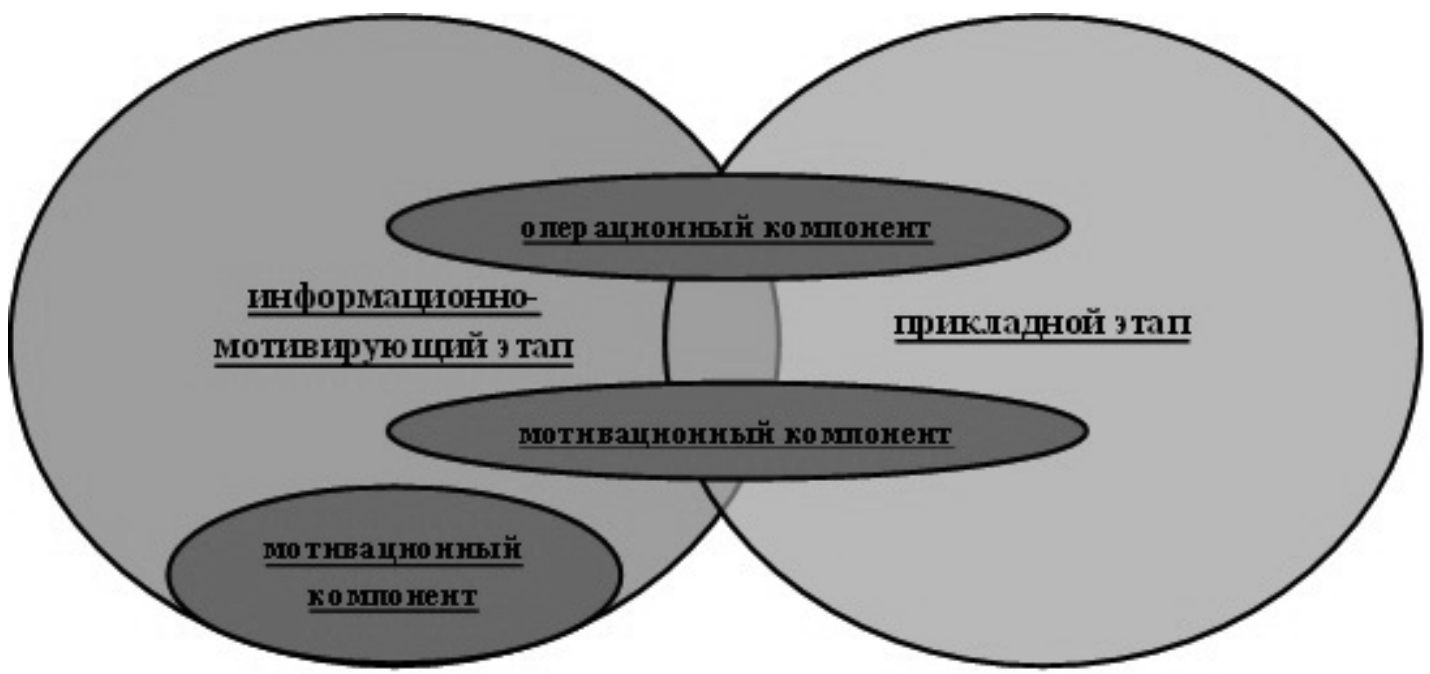

Рис. 1. Взаимосвязь информационно-мотивирующего и прикладного этапов через мотивационный и операционный компоненты

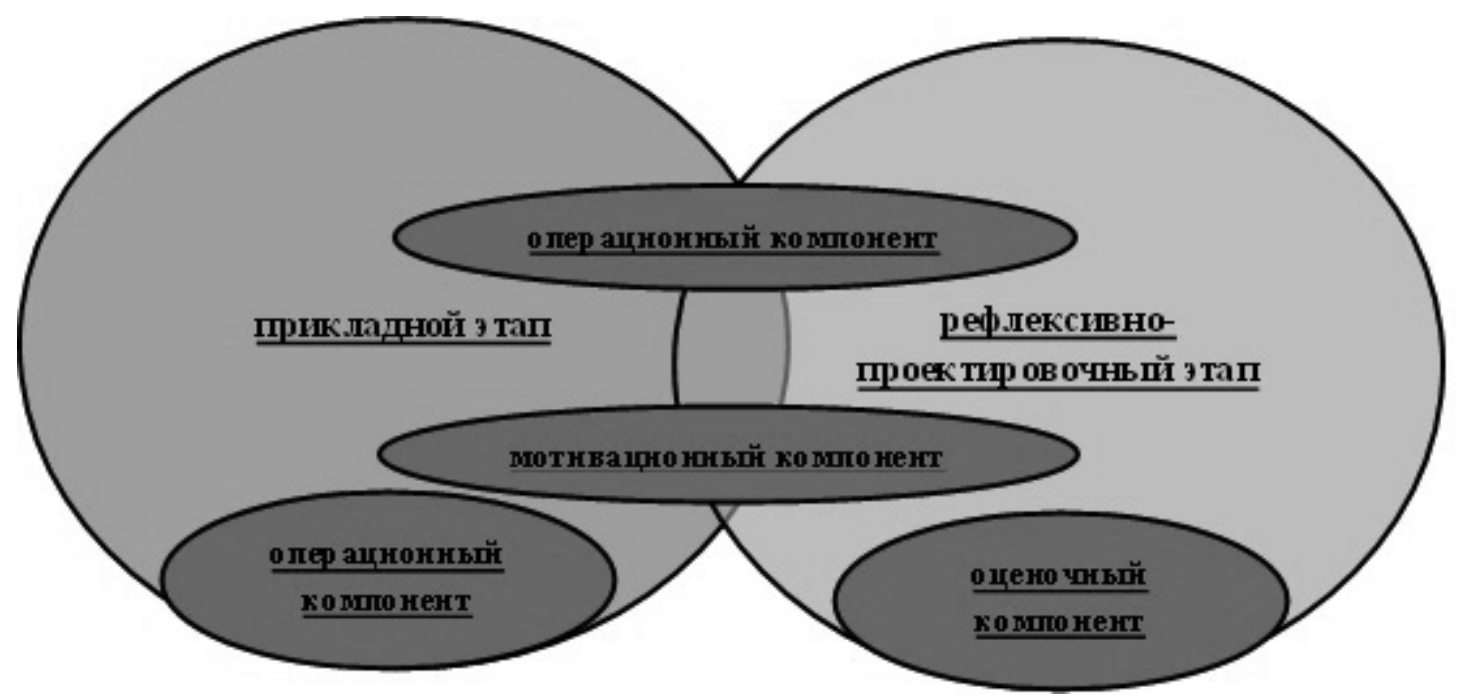

Рис. 2. Взаимосвязь прикладного и рефлексивно-проектировочного этапов через мотивационный и операционный компоненты 
скольких этапов, поэтому нет четкой границы между этапами. Каждый этап связан с предыдущим и последующим, что отражается на целостности модели и непрерывности процесса формирования дидактико-методической компетентности будущих учителей информатики.

На информационно-мотивирующем этапе начинается формирование мотивационного (основного компонента для этого этапа) и операционного (дополнительного) компонентов дидактико-методической компетентности будущих учителей информатики с последующим переходом на прикладной этап. На прикладном этапе формируются мотивационный (в качестве дополнительного компонента для этого этапа) и операционный (основной) компоненты. Рефлексивно-проектировочный этап продолжает формирование мотивационного (дополнительного) и операционного (дополнительного) компонентов дидактико-методической компетентности, а также начинает формировать оценочный (основной) компонент для этого этапа.

Формирование компонентов дидактико-методической компетентности будущих учителей информатики (мотивационного и операционного) при переходе с первого этапа (информационно-мотивирующего) на второй этап (прикладной) представлено на рисунке 1.

Формирование компонентов дидактико-методической компетентности будущих учителей информатики (мотивационного и операционного) при переходе со второго этапа (прикладного) на третий этап (рефлексивно-проектировочный) представлено на рисунке 2.

При разработке модели дидактико-методической компетентности будущего учителя будем основываться на следующих методологических подходах к обучению: личностно-ориентированном, системном, деятельностном и компетентностном.

Личностно-ориентированный подход утверждает представления о деятельностной и творческой сущности человека как личности. Компетентность и компетенция изучаются в системе черт, свойств и личностных качеств субъекта [6, с. 175-176]. Сущность системного подхода в формировании дидактико-методической компетентности будущих учителей заключается в том, что относительно самостоятельные компоненты компетентности рассматриваются во взаимосвязи, в системе с другими, при этом любой объект рассматривается и как система, и как элемент более крупной, объемлющей его системы [5, c. 58-62]. Деятельностный подход ориентирует на исследование педагогических процессов и явлений в логике целостного рассмотрения всех основных компонентов деятельности: потребностей мотивов, целей, действий, операций, способов регулирования, контроля и анализа достигаемых результатов. Компетентность определяется деятельностью и одновременно является её предпосылкой [4, с. 34-41]. Компетентностный подход обеспечивает выявление возможностей совершенствования процесса образования через согласование его организации, содержания, результатов с потребностями социума, определение и обоснование соответствующего состава компетенций, позволяющих личности продуктивно взаимодействовать с окружающей средой [1, с. 469-473].

Положим вышеупомянутые методологические подходы в основу модели формирования ДМК будущих учителей информатики. Выделим для своего исследования следующие компоненты: мотивационный, операционный, оценочный, которые учитывают особенность данного вида компетентности и позволяют ее рассматривать системно и применить критерии при оценке сформированности дидактико-методической компетентности учителя.

Мотивационный компонент модели формирования дидактико-методической компетентности будущих учителей информатики определим на основе личностноориентированного подхода к обучению будущего учителя информатики, так как он включает в себя ценностные установки, связанные с будущей педагогической деятельностью: осознание значимости деятельности учителя информатики в современном мире, мотивы и цели получения образования в этом направлении и его совершенствования.

Операционный компонент модели формирования дидактико-методической компетентности будущих учителей информатики мы выделяем, основываясь на системном и деятельностно-компетентностном подходах. Данный компонент предполагает использование общепедагогических, предметных, психологических знаний, а также знаний в области методики преподавания предмета для: организации процесса обучения информатике, проведения внеклассной работы и научно-исследовательской работы с обучающимися.

Оченочный компонент модели формирования дидактико-методической компетентности будущих учителей информатики выделим с учетом использования личностно-ориентированного, системного и деятельностно-компетентностного подходов. Оценочный компонент включает в себя аналитические и рефлексивные знания, умения, которые позволяют анализировать результаты педагогической деятельности, устанавливать причинно-следственные связи при организации процесса обучения информатике, при проведении внеклассной работы и научно-исследовательской работы с обучающимися. Также неотъемлемыми элементами этого компонента являются прогнозирование эффективности используемых форм, средств и методов обучения, сравнение прогнозов с результатами, и коррекция своей 
деятельности с учетом самооценивания.

Определим функции каждого компонента.

1. Функциональное назначение мотивационного компонента модели ДМК будущих учителей информатики заключается в формировании ориентаций и мотивов к дидактико-методической деятельности, а также личностных качеств, определяющих поведение по отношению к обучающимся в педагогической деятельности, накоплении положительного опыта дидактико-методической деятельности, повышении мотивации и стремления к личностно-профессиональному росту; преодолении трудностей и решении задач профессиональной деятельности.

2. Функциональное назначение операционного компонента модели ДМК будущих учителей информатики состоит в формировании и применении на практике знаний и умений по общей теории обучения, по методике конкретной предметной области и по дисциплинам специальной подготовки, расширении технологического инструментария деятельности (методы, приемы, средства).

3. Функциональное назначение оченочного компонента модели ДМК будущих учителей информатики включает знания и умения по внешней диагностике (оценивание и корректирование деятельности обучаемых) и внутренней диагностике (самоанализ и корректирование своей деятельности).

Необходимо подчеркнуть, что дидактико-методическая компетентность будущих учителей информатики, как и любой другой вид компетентности, имеет уровневый характер. Степень сформированности компонентов дидактико-методической компетентности будущего учителя информатики позволяет выделить уровни их сформированности.

Исследователи по-разному определяют уровни сформированности дидактико-методической компетентности. Так, например, О.Б. Даутова в своих работах рассматривает репродуктивный, эвристический, креативный уровни сформированности дидактической компетентности [3, с. 153-155]. Ж.А. Мовсесян и Н.В. Грызлова выделяет три уровня сформированности дидактической компетентности: низкий, средний и высокий [5, с. 59]. Возьмем за основу в своем исследовании деление на низкий, средний, высокий уровни, что является достаточным для дифференцирования одного уровня от другого по основным характеристикам.

Низкий уровень сформированности дидактико-методической компетентности будущих учителей информатики характеризуется слабой мотивацией к изменениям, использованию нового педагогического инструмента- рия, применением шаблонов и действиями по образцу в профессиональной педагогической деятельности, подверженностью стереотипному мышлению, отсутствием ориентации на междисциплинарные взаимодействия, полным или частичным отказом от самообразования и рефлексии.

На среднем уровне сформированности дидактико-методической компетентности будущих учителей информатики происходит переход от стереотипного мышления к активной познавательной деятельности, применение различных форм и методов обучения. Обучающиеся демонстрируют критическое мышление по отношению к своей профессиональной деятельности, грамотное использование дидактических умений, способность к саморефлексии, внесение изменений в деятельность с учетов результатов процесса обучения.

Высокий уровень сформированности дидактико-методической компетентности будущих учителей информатики проявляется в творческом подходе к своей профессиональной педагогической деятельности, способности к ее проектированию и прогнозированию. Данный уровень характеризуется высокой адаптивностью к изменениям образовательной среды, применением современных, разработкой собственных методов и технологий обучения, эффективным применением дидактических знаний и умений в процессе решения дидактических задач, а также высоким уровнем саморефлексии.

Определим основные критерии сформированности дидактико-методической компетентности будущего учителя информатики для каждого ее компонента.

Основные критерии сформированности мотивационного компонента ДМК учителя информатики:

- определение основных целей личного образования в предметных областях: информатика, психология, педагогика, методика преподавания информатики и т.п.;

- реализация поставленных целей через изучение дисциплин специальной, методической подготовки бакалавриата по профилю Информатика;

- реализация поставленных целей через систему повышения квалификации (офлайн-обучение), дистанционное обучение (онлайн-обучение);

- участие в профессиональных конкурсах по направлению «Педагогическое образование» профиль «Информатика»;

- участие в деятельности учебных заведений в качестве помощника учителя информатики, классного руководителя, организаторов олимпиад, образовательных курсов и т.п.

При определении критериев сформированности операционного и оценочного компонентов будем по- 
нимать готовность к их выполнению, реализации, применению, использованию, так как рассматривается процесс подготовки будущего учителя информатики при обучении в бакалавриате.

Основные критерии сформированности операционного компонента ДМК учителя информатики:

- реализация основ теории и методики обучения информатике в профессиональной деятельности;

- использование знаний и умений специальной и методической подготовки для осуществления учебной и методической деятельности по информатике;

- выполнение требований образовательных стандартов через реализацию образовательных программ по информатике;

- использование различных форм организации учебной деятельности в соответствии с задачами процесса обучения информатике;

- использование различных методов и средств обучения в соответствии с задачами процесса обучения информатике;

- применение знаний и умений специальной и методической подготовки для организации внеклассной работы по информатике;

- применение знаний и умений специальной и методической подготовки для решения исследовательских задач в области преподавания информатики;

- применение знаний и умений специальной и ме- тодической подготовки для организации научноисследовательской деятельности учащихся по информатике;

- использование информационных технологий для повышения эффективности процесса обучения информатике.

Основные критерии сформированности оценочного компонента ДМК учителя информатики:

- проведение аспектного анализа урока и внеклассных мероприятий по информатике, включая анализ собственной деятельности;

- определение уровня и качества знаний, обучающихся по информатике;

- прогнозирование эффективности применяемых форм, средств, методов и приемов обучения информатике;

- сравнение прогнозов с результатами обучения информатике с целью коррекции педагогической деятельности.

Таким образом, модель интегрирует три основных структурообразующих компонента данной компетентности и раскрывает их функции и этапы формирования, что позволяет выделить критерии сформированности, на основе которых могут быть разработаны показатели сформированности ДМК, а также определены средства и методы формирования дидактико-методической компетентности будущего учителя информатики в период обучения в ВУЗе, способствующие ее эффективному формированию.

\section{ЛИТЕРАТУРА}

1. Веневцева А.А. Методологические подходы к формированию информационно-коммуникативной компетенции у студентов средних образовательных учреждений. // Фундаментальные исследования. - № 12-3, 2011. - С. 469-473.

2. Грызлова Н.В. Неопределенные задачи как средство формирования у будущих учителей математики дидактико-методической компетентности: дисс. ... канд. пед. наук. - Волгоград, 2004. - С. 14-35.

3. Даутова 0.Б. Изменение учебно-познавательной деятельности школьника в современном образовании.: дисс. ... д. пед. наук.: Санкт-Петербург, 2011. - C. 153-155.

4. Ильязова М.В. Компетентностный подход в системе методологического анализа. // Успехи современного естествознания. - №4, 2007.

5. Мовсесян Ж.А. Формирование дидактической компетентности студентов педагогического вуза в процессе самостоятельной работы.: дисс. ... к. пед. наук.: Саранск, 2017. - С. 58-62.

6. Сластенин В.А. Педагогика. Учеб. пособие для студ. высш. пед. учеб. заведений.: М.: Издательский центр «Академия», 2013. - С. 175-176.

() Фаворская Екатерина Александровна (favorskayaea@mail.ru). 